\title{
METEORITE PLACER DEPOSITS OF ANTARCTICA
}

\author{
by
}

Ursula B. Marvin

The chance discovery in 1969 of several dark rocks on a patch of bare ice in Antarctica has led to an extensive international program of meteorite recovery and research. More than 5000 specimens have been collected, probably representing several hundred meteorites including some rare and previously unknown varieties. Isotopic determinations of terrestrial residence times indicate that many Antarctic meteorites fell to Earth several hundred thousand years ago. They apparently represent a population of Earth-crossing planetary fragments older than meteorites found on other continents, where few survive weathering for more than 10000 years. These deposits of extraterrestrial samples are yielding fresh clues to the earliest history of the solar system and generating new lines of research on the dynamics of large ice sheets.

\section{Discovery at the Yamato Mountains}

The first meteorites discovered in Antarctica were picked up in 1912 by the Australian geologist Douglas Mawson, who found a dark stony meteorite in the snow near the coast of Adelie Land. A second was found in 1961 in the Humboldt Mountains where a Soviet Union party discovered two fragments of the same nickel-iron meteorite lying in a moraine about $40 \mathrm{~m}$ in front of the ice margin. Two more were found by U.S. scientists in the Thiel Mountains in 1962 and the Neptune Mountains in 1964. The latter was a single mass of metallic nickel-iron lying on a rocky surface, and the Thiel Mountains discovery was of a rare pallasite broken into two fragments on a glacial moraine.

In December 1969 a team of Japanese glaciologists, working inland from the Yamato Mountains, came upon first one stony

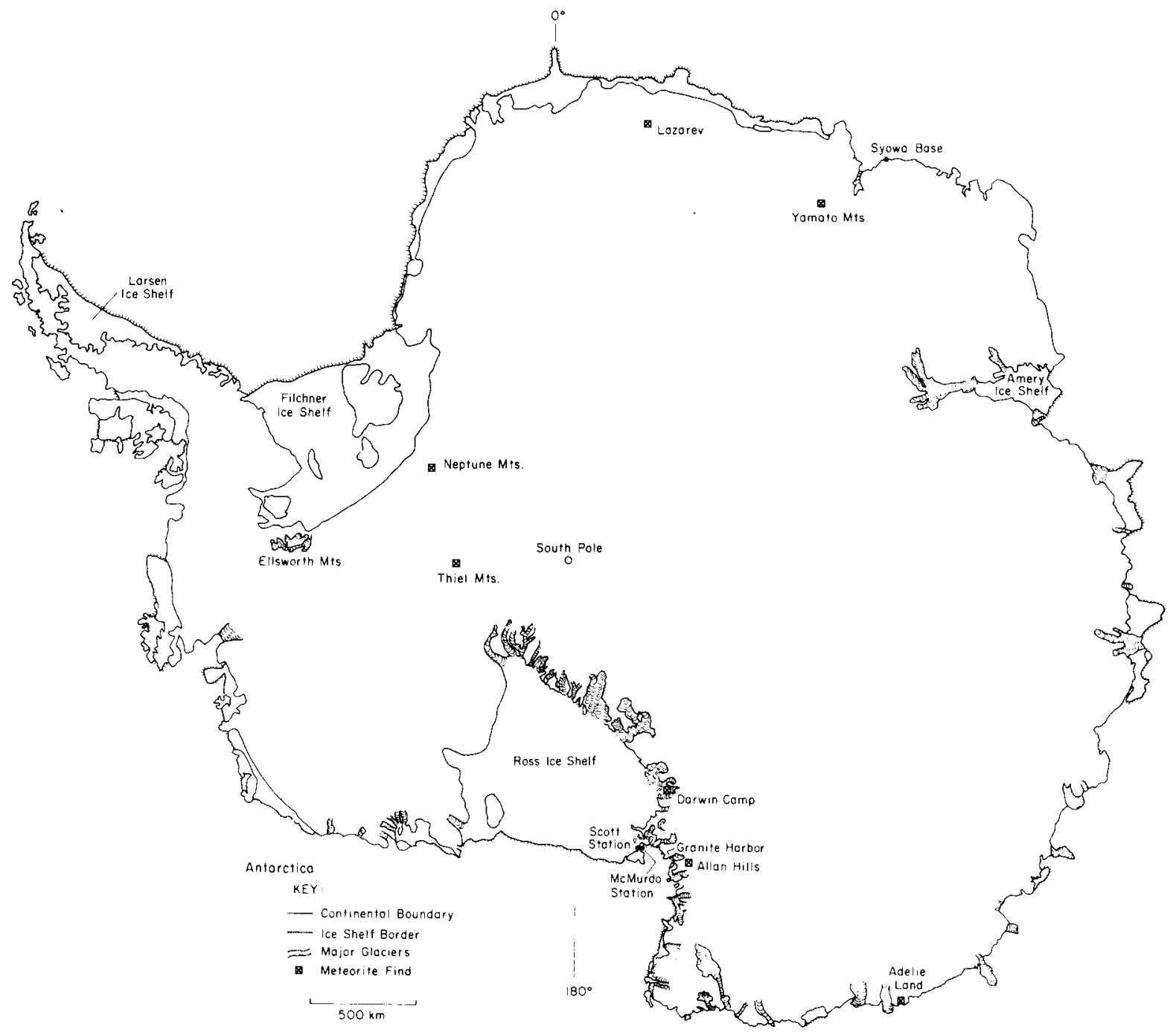

Figure 1: The Antarctic continent showing locations of meteorite discoveries. The Transantarctic Range borders the northeast side of the Ross Ice Shelf. 
meteorite and then eight more on a small exposure of windswept ice at approximately $70^{\circ} \mathrm{S}, 37^{\circ} \mathrm{E}$ (Fig. 1). Because it was known that meteorites often burst in the atmosphere and fall as showers, or break apart on striking the ground, the nine pieces from the Yamato Mountains ice field were assumed to be fragments of one meteorite. However, in August 1973, the Japanese petrologist Makato Shima reported to the Meteoritical Society meeting in Davos, Switzerland, that each of the first four Yamato specimens studied belonged to a different class of stony meteorites.

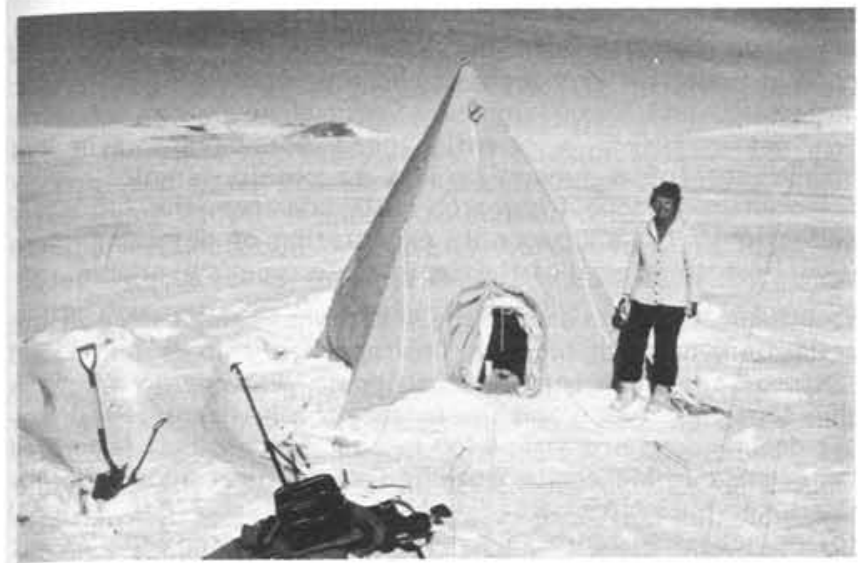

Figure 2: The author pitching a tent at the Allan Hills in the noonday sun at $-12^{\circ} \mathrm{C}$.

Dr. Shima's finding was unique. Only rarely have two separate meteorite falls been known to strike the same target area, and the probability is infinitesimal that four falls will strike the same site. Clearly, something was special about the Yamato meteorite occurrence. Meteorites falling at different times and places had apparently been frozen-in, carried toward the coastline by the slowly moving icesheet and concentrated in a small area - "placer deposits" of extraterrestrial specimens. Japanese scientists suspected that the concentration formed because the Yamato Mountains acted as a barrier to ice flow.

W.A. Cassidy of the University of Pittsburgh (U.S.A.) decided to follow up this idea by searching for stagnant patches behind the Transantarctic Range on the opposite side of the continent near McMurdo Station. Cassidy recalls that his original proposal met with harsh criticism from scientists to whom meteorite-hunting expeditions, especially into a vast unknown territory, were a novel and not very promising idea. Meanwhile. Japanese teams returned to the Yamato Mountains, and by the austral summer of 1975-76 they had added nearly 1000 meteorite specimens to the world's collections.

\section{The United States Collection and Curation Program}

Dr. Cassidy made his first trip to Antarctica in 1976 accompanied by Dr. E. Olsen of the Field Museum in Chicago, U.S.A. At McMurdo Station they joined forces with Japanese scientists to search nearby areas for meteorites, agreeing to share equally all specimens discovered. This arrangement continued for three field seasons.

After searching air photographs the party located their first camp on a patch of blue ice near Mt. Baldr in the Transantarctic Range where they discovered two stony meteorites in the first $2 \cap$ minutes. Six weeks later, however, after searching a number of bare ice patches by helicopter no more meteorites had been found. As the end of the season approached and the party prepared to leave, a helicopter pilot offered to show them a patch of bare ice studded with dark rocks near the Allan Hills at about $76^{\circ} \mathrm{S}, 156^{\circ} \mathrm{E}$. They landed beside a stony meteorite, then found an iron nearby. On two visits to that site they collected 45 specimens, representing about 10 meteorites. Three fragments fitted together like pieces of a jigsaw puzzle, and another group of 33 lay close together and were counted (and later confirmed) as parts of one fall.

The pilot had led them to what has proved to be an extraordinarily rich concentration area - perhaps the richest in that portion of Antarctica. Searches have also been made and meteorites found in several other ice fields on the interior side of the Transantarctic Range, but field parties have returned to the Allan Hills every season since 1976 and collected more than 1000 specimens there.

For those fortunate enough to take part, meteorite collecting in Antarctica is a glorious adventure. Promising search areas are selected by helicopter reconnaissance and tent camps set up nearby (Fig. 2). Parties of two or more now work large areas on snowmobiles, often following systematic traverses.

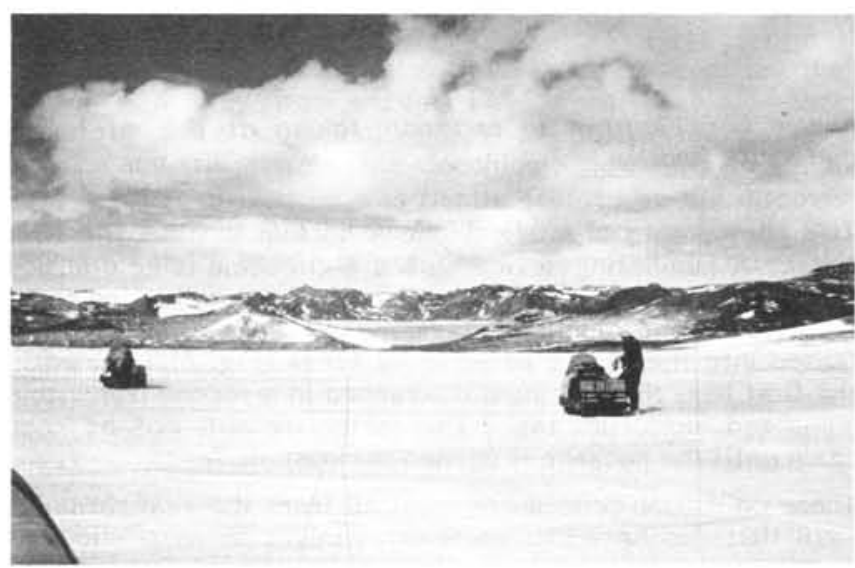

Figure 3: Heading toward Man Haul Bay in the Allan Hills. Permocarboniferous strata in these mountains contain coal, petrified wood and Glossopteris seeds and leaf imprints.

On bright days, humps and hollows in the snow drifts cast dark shadows and the region seems full of meteorites. On dull days, with no shadows, the snowmobiles buck and plunge over drifts a driver cannot see.

It is exhilarating to work on the ice plateau amid spectacular mountain scenery with 24 hours of sunlight (Fig. 3). But no excitement compares with sighting a dark rock that proves from its shiny fusion crust. chondritic texture, or flightoriented form (Fig. 4) to be a meteorite. When that occurs, one swerves beside it, switches off the ignition, and waits to be noticed. Field party members always keep within sight of

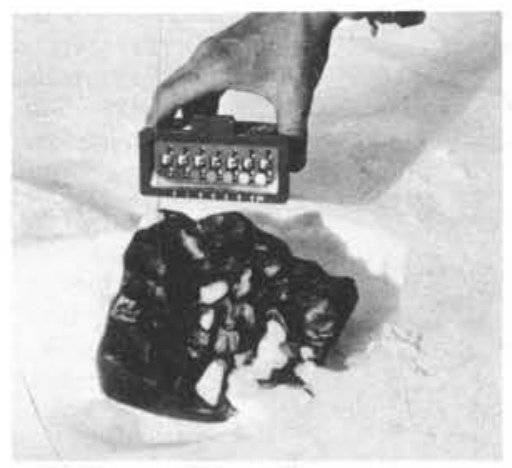

Figure 4: An iron meteorite photographed in situ beside a hand held numbering device with a $6-\mathrm{cm}$ scale. This specimen was found in 1981 to the west of the Allan Hills concentration zone. Its square section and smooth sides probably reflect the structure of a type of iron called a hexahedrite. The "thumb prints" on top are ablation features. 
each other and each frequently turns to check the others. A stopped machine and a certain style of triumphant wave signals a meteorite. One's partner comes roaring to the site (Fig. 5).

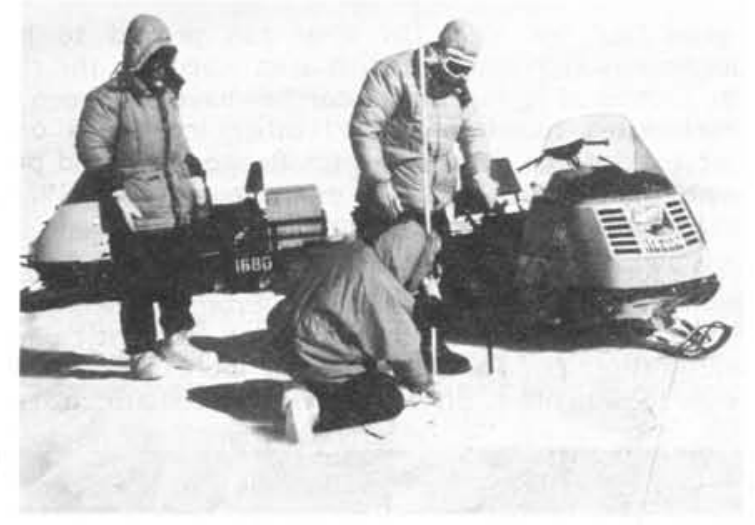

Figure 5: Flag-raising and note-taking at the site of a meteorite find.

Two photographs are taken (one a backup in case the first fails). A numbering device with a $6-\mathrm{cm}$ scale is held beside the specimen. Teflon bags are slid out of the collecting pack, teflon tape and aluminum tags found, and the meteorite is teased into the bag or lifted in by tongs (Fig. 6). Sealed in the first bag, the specimen is wrapped in a second one with a numbered aluminum tag. The meteorite will not be seen again until the package is opened in Houston, Texas.

These collection procedures resulted from the realization in 1976 that the Antarctic meteorites might be as precious as lunar samples. Indeed, some bear a striking resemblance to the lunar breccias collected by the Apollo astronauts. Since they were preserved in the coldest, most sterile environment on Earth, should they not be kept sterile for isotopic and trace element analyses? Should not individual, well-documented samples be distributed to consortia of scientists for a series of investigations? In short, should not the Antarctic meteorites be collected and curated as methodically as the lunar samples?

In the summer of $1977, \mathrm{Dr}$. Cassidy sent a questionnaire to members of The Meteoritical Society and other interested scientists asking for suggestions on optimum collecting procedures. Before the 1977-78 field season began, wide-ranging discussions led to a cooperative agreement between the

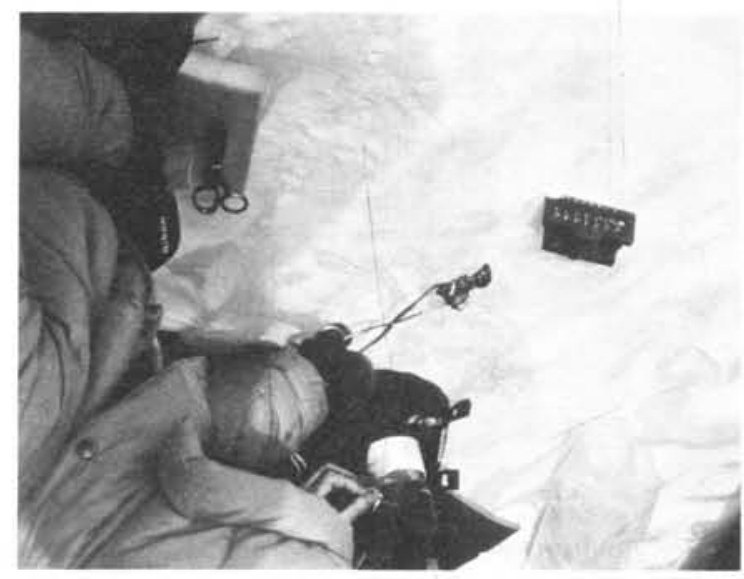

Figure 6: A small meteorite is lifted with stainless steel tongs.
National Science Foundation, the Smithsonian Institution, and the National Aeronautics and Space Administration (NASA). This directed that the Antarctic specimens be collected by sterile procedures, kept frozen, and shipped to the Curatorial Facility at the NASA Johnson Space Center at Houston, where they would be opened in nitrogen-filled glove boxes like those used for lunar samples. The subdivision and allocation of these materials would be carefully documented, again in the manner of the lunar samples. As long as the working agreement with Japanese field parties continued, specimens would be sawed open at Houston and half of each sent to the Division of Polar Programs in Tokyo.

Scientists familiar with the lunar program, however, find certain major differences between the handling of Antarctic meteorites and lunar samples. Strict security requirements are not required; a scientist need not be the principal investigator of a funded project to obtain samples. Any scientist may request research materials from the Antarctic collections with a reasonable expectation of obtaining them if sufficient material of the appropriate type is available.

To inform scientists around the world what samples are in the collection, as each piece is unwrapped a chip is taken and sent to the Smithsonian Institution in Washington where a thin section is made and the meteorite classified. Preliminary descriptions are assembled in a newsletter that is mailed (on request to Meteorite Working Group, Lunar and Planetary Institute, 3303 NASA Road 1, Houston, Texas 77058, U.S.A.) to specialists in more than a dozen countries. Samples for research are obtained by detailing one's requirements in a letter to the Meteorite Working Group. To date, well over 1200 samples have been distributed from the U.S. collection to more than 90 research groups in 13 countries. A similar program has been instituted in Japan.

\section{"Meteorites" and "Specimens"}

It is important to emphasize the distinction between specimens and meteorites. All the pieces of a given body that enter the atmosphere are counted as a single meteorite and named after the nearest post office or natural feature. For example, when a spectacular shower of 100000 stones fell at Pultusk, Poland, at 7:00 o'clock on the evening of January 30, 1868 , the individual specimens were all catalogued under the single name "Pultusk".

Meteorite collecting and cataloguing began in a serious way at the beginning of the 19th century; by 1966 about 2100 meteorites (represented by hundreds of thousands of specimens) were known worldwide. How many meteorites have been added by discoveries in Antarctica is not known and may never be because large numbers of them are pieces of ordinary meteorite types that could have fallen singly or in showers. Some of the specimens, however, represent previously unknown or rarely encountered varieties.

\section{The Importance of Meteorites}

Meteorites carry a wealth of information on the physical character, chemical composition, and age of their parent bodies, and on the types and intensities of the radiation they encounter as they orbit unshielded through space. There are three main types of meteorites: stones, irons, and stonyirons, presumably derived respectively from silicate crusts and mantles, metallic cores, and transition zones of bodies disrupted by collisions. Statistics compiled from about 700 witnessed falls during the past 200 years indicate that 93 per cent of meteorites are stones, six per cent are irons, and one per cent are stony-irons.

On the basis of textures and trace element compositions, the irons have been subdivided into groups which appear to have derived from at least 62 different parent bodies. Most may be fragments of planetary cores, but some probably come from metallic pods embedded in the silicate layers of their parent bodies. 
Stony-irons are of two main varieties: pallasites, which consist of individual olivine crystals enclosed in a larger nickel-iron host - presenting the problem of why the grains did not float out while the metal was molten - and mesosiderites, which are brecciated admixtures of silicates and metal.

Stony meteorites are characterized as chondrites or achondrites depending on the presence or absence of chondrules. These are small $(1-4 \mathrm{~mm})$ spherical silicate bodies of disputed origin having no counterparts in terrestrial rocks, although similar bodies were found in certain lunar breccias. Chondrites, by far the most abundant meteorites ( 90 per cent of the stones), are fragmented aggregates that have never melted. They exhibit a range of textures reflecting different degrees of thermal metamorphism, the most interesting chondrites being the least recrystallized. The latter include the rare carbon- and water-bearing group called carbonaceous chondrites, some of which appear to contain a record of primary nebular condensation processes. Achondrites are differentiated igneous rocks, many of them brecciated. Some achondrites originated as magmatic cumulates, others are samples of basaltic lava flows.

Isotopic age determinations by the $\mathrm{U} / \mathrm{Pb}, \mathrm{Rb} / \mathrm{Sr}$, and $\mathrm{K} / \mathrm{Ar}$ methods show that most meteorites are $800 \mathrm{Ma}$ older than the Earth's oldest dated crustal rocks, which are about 3800 $\mathrm{Ma}$ old. Certain terrestrial rocks, meteorites, and lunar rocks fall on isochrons which project back to a common time of origin $4600 \mathrm{Ma}$ ago, which is taken as the birthdate of the solar system. Meteorites therefore include the oldest as well as the most primitive of planetary samples.

Several lines of evidence point to asteroids as the most likely parent bodies of most meteorites. The orbits calculated from several photographed meteorite falls originate in the asteroid belt between Mars and Jupiter (Fig. 7). Telescopic reflectance spectra of asteroidal surfaces show close matches to spectra measured in the laboratory on crushed samples of several types of meteorites. The parent bodies must have

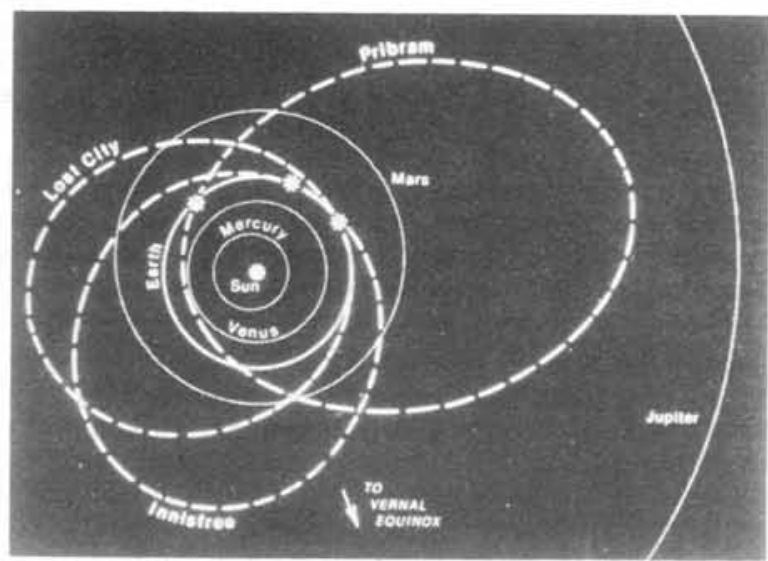

Figure 7: The elliptical, Earth-crossing orbits calculated from the photographed trajectories of three meteorite falls: Pribam, Czechoslovakia, 1959; Lost City, Oklahoma 1970; and Inisfree, Alberta 1977.

been asteroid size ( $<1000 \mathrm{~km}$ in diameter) because cooling rates, calculated from the metallurgical properties of iron meteorites, are only 1 to $10^{\circ} \mathrm{C}$ per million years, much too rapid for metals insulated within bodies as large as the Moon. Furthermore, some irons and stony-irons contain tridymite and cristobalite, high temperature but low-pressure polymorphs of $\mathrm{SiO}_{2}$.

\section{New and Unusual Meteorites in the Antarctic Collections}

Specimens collected in the Antarctic program include a number of rare or previously unknown varieties of meteorites. Among the more interesting discoveries are a diamond- bearing iron meteorite, several species of achondrites, and some carbonaceous chondrites.

Diamond-bearing Iron Meteorites: For many years the evidence that irons formed in small parent bodies appeared to be contradicted by the presence of diamonds in the Canyon Diablo iron meteorite, which struck the Earth with such explosive force that it excavated the spectacular $1.2-\mathrm{km}$ diameter Meteor Crater in northern Arizona. Because terrestrial diamonds originate under high static pressures deep in the Earth's crust, it was assumed that the diamond-bearing irons formed in the cores of large parent bodies. Then, in the early 1960s, diamonds were created artificially by passing shockwaves through carbon, and the resulting clumps of minute crystals bore a striking resemblance to the small, black, diamond-bearing masses in Canyon Diablo. Controversy raged for several years over whether the meteoritic diamonds were stable minerals, formed under hydrostatic pressure, or metastable, shock-produced phases.

Searches for meteoritic diamonds failed to confirm their presence in any iron except in Canyon Diablo. Shock pressures were sufficiently high to transform quartz to coesite and stishovite in the Coconino Sandstone beneath the crater floor. The issue was finally decided by the discovery that the Canyon Diablo diamonds are intergrown with lonsdaleite, a shock-produced hexagonal polymorph of carbon.

The second known diamond-bearing iron meteorite was discovered in the Allan Hills ice fields of Antarctica in 1977. In contrast to the huge tonnage estimated for Canyon Diablo iron, the Antarctic specimen weighed only $10 \mathrm{~kg}$ and had a heat-altered zone at the surface typical of irons that decelerate in the atmosphere and strike the Earth at the velocity of free fall. This iron was associated with no known or suspected impact crater, so its diamond-lonsdaleite intergrowths are interpreted as evidence of a collision in space.

Ureilites: Collisions in space had already been invoked to account for small diamond-lonsdaleite masses that occur in a rare class of stony meteorites called ureilites. Only eight ureilites were known in 1969 but six more had been collected in Antarctica by 1980 . These meteorites, all small specimens, consist mainly of olivine with subordinate clinopyroxene (chiefly pigeonite). Several were seen to fall over populated areas; none sustained violent impacts. They too bear the imprint of preterrestrial high-velocity shock events.

Ureilites are puzzling mixtures in which ultramafic silicate rocks, formed either as partial melts or plutonic cumulates, lie in a matrix of carbonaceous material containing troilite (FeS) and $\mathrm{Ni}$-poor $\mathrm{Fe}$-metal. The origin of the ureilites remains in dispute, but the Antarctic collections have extended the range of compositions by providing new $\mathrm{Mg}$-rich and $\mathrm{Fe}$-rich varieties. One of the specimens from the Allan Hills has the most fayalitic olivine $\left(\backsim \mathrm{FO}_{76}\right)$ and the only augite observed in ureilites. Every additional sample contributes to our understanding of these remarkable igneous and shock-metamorphosed rocks.

Diogenites: Recent studies on one Antarctic achondrite, a diogenite, have turned up tiny liquid and water vapour-filled inclusions within orthopyroxene crystals. These appear to have been trapped when the host crystals equilibrated, at about $900^{\circ} \mathrm{C}$ and perhaps $9 \mathrm{~kb}$. This new line of evidence suggests that diogenites may have come from considerable depths within asteroidal parent bodies.

Shergottites: Shergottites are another rare and interesting type of achondrite. Two specimens were known previously, and two more have been found in Antarctica. Shergottites are shocked samples of volatile-rich basaltic lavas in which the plagioclase crystals have been transformed in situ to dense glass. Measurements by several different isotopic methods indicate that the shergottites crystallized only about $1300 \mathrm{Ma}$ ago. This is an astonishingly young age for lava 
eruptions on small, asteroid-sized bodies which, judging from the metallurgical character of iron meteorites, appear to have had cores of metal that solidified as early as $4500 \mathrm{Ma}$ ago. Basaltic volcanism on the Moon, which is nearly twice the diameter of the largest asteroid, appears to have ended as early as $3100 \mathrm{Ma}$ ago.

The search for a heat source adequate to produce the young shergottite lavas has led a number of investigators to propose that they come from Mars. The dynamic problem of projecting Martian surface materials into earth-crossing orbits by high-velocity impacts is difficult but not insurmountable. The intriguing possibility that they originated from Martian volcanoes adds much excitement to the search for more shergottites in Antarctica.

Polymict Eucrites: The most abundant achondrites are basaltic pyroxene-plagioclase lavas and cumulate rocks called eucrites and howardites. Both are brecciated, but eucrites have traditionally been defined as monomict, and howardites as polymict, breccias. The old definitions proved inadequate, however, when the Antarctic concentrations at both the Allan Hills and the Yamato Mountains yielded numerous samples of a new variety that is polymict but contains none of the howarditic Mg-rich pyroxenes. Thus, a new class called polymict eucrites exists, of which only one possible example is known outside Antarctica - the Macivini meteorite from South Africa. Sufficient numbers of samples have been collected to allow several consortia of scientists to study polymict eucrites, their genetic relationship to other meteorites, and their enigmatic distribution on Earth.

Carbonaceous Chondrites: A rare carbon- and water-rich variety of stones called carbonaceous chondrites (Type $\mathrm{Cl}$ ) have bulk compositions similar to that of the body of the Sun, excluding the volatiles in the solar atmosphere. These meteorites consist mainly of hydrous clay-like silicates with lesser amounts of carbonates, sulfates, and magnetite. Despite their name, which is a legacy of the past, $\mathrm{Cl}$ chondrites contain no chondrules. They appear to have accreted from cold components of the solar nebula and never subsequently been heated above about $150^{\circ} \mathrm{C}$. Some scientists think the $\mathrm{Cl}$ meteorites are fragments from the surfaces of asteroids situated farthest from the Sun in the outer reaches of the asteroid belt. Others believe they may have been released by the wasting of ices from the nuclei of comets orbiting close to the Sun.

Three other groups of carbonaceous chondrites (C2, C3, C4) are mixtures of high-temperature refractory inclusions and chondrules in fine-grained matrices of mineral fragments and carbon. Since 1973, a number of isotopic anomalies, particularly an enrichment in ${ }^{16} 0$ that cannot be ascribed to any solar system process, have been found in the inclusions of these three groups. These anomalies are believed to have originated outside the solar system, perhaps from the explosion of a nearby supernova. Thus carbonaceous chondrites are true "genesis rocks" preserving evidence of galactic events that led to the formation of the solar system.

The expectation of finding carbonaceous chondrites in Antarctica was a primary reason for prescribing sterile collecting techniques. Some carbonaceous chondrites contain small amounts of hydrocarbon compounds including amino acids, fatty acids, and porphyrins. The amino acids occur in racemic mixtures generally interpreted as evidence of nonbiologic, extraterrestrial origin. Their presence in meteorites $4.6 \mathrm{Ga}$ old suggest that the acids and other hydrocarbon compounds were indigenous in the solar nebula. This view has been strengthened by spectral measurements of compounds such as $\mathrm{CH}_{3} \mathrm{CN}$ in comets, and microwave detection of organic molecules in interstellar space. However, the organic materials in meteorites may have formed after the accretion of their parent planets.

When amino acids were originally found in carbonaceous chondrites from other continents, terrestrial contamination was suspected and in some instances confirmed. By the 1970 s techniques had been developed that effectively ruled out contamination. Nevertheless, organic chemists were interested in analyzing carbonaceous chondrites from the Antarctic ice, which is as sterile as triply distilled water.

The effort to preserve them in their pristine state came just in time for the first carbonaceous chondrite discovery in the Allan Hills, Eight specimens have been collected there, and about 28 in the Yamato Mountains area. All of these specimens are small, and the majority are of type C2. But those analyzed to date contain about 20 amino acids, the most abundant of which, measured in quantities of a few nanomoles per gram, are glycine and $\gamma$-aminobutyric acid. Comparative analyses of their surfaces and interiors show that the Antarctic specimens are free of terrestrial contaminants. Little doubt remains, therefore, that carbonaceous chondrites carry to Earth samples of some of the organic molecules that predated the advent of life in the solar system.

\section{Terrestrial Residence Times and Meteorite Distributions}

Not only have new varieties of meteorites been found, but surveys of terrestrial residence times, based on measurements of one or more of the cosmic-ray produced isotopes ${ }^{26} \mathrm{Al},{ }^{14} \mathrm{C},{ }^{36} \mathrm{Cl},{ }^{53} \mathrm{Mn},{ }^{81} \mathrm{Kr}$ and ${ }^{10} \mathrm{Be}$, indicate that many of the Antarctic stones fell to earth between 10000 and 750000 years ago, with a clustering of ages at 100000 to 300000 years. Most meteorites collected on other continents fell within the past 200 years, although a few date back to 50000 years or more. The Antarctic meteorites thus represent a distinctly older sample of planetary debris that has occupied Earth-crossing orbits. Whether or not this explains the presence only in Antarctica of a class such as the polymict eucrites which may have been destroyed elsewhere by weathering is one of the many problems of meteorite distribution.

The relative proportions of meteorites cited in an earlier section were based on frequencies of types produced by 200 years of witnessed falls. In Antarctica, where no falls have been observed, proportions must be based on the masses of each variety collected in concentrations that have been accumulating through several hundred thousand years. Certain differences are beginning to appear between the yields at the Yamato and Allan Hills ice fields. In both areas the most frequently collected chondrite specimens weigh about 8 g. The specimens from the Yamato Mountains show a consistent bias toward lower masses, however, and there are fewer of them per unit area. Specimens from the Allan Hills show a bias toward higher masses and occur in denser concentrations.

During the first five field seasons in the Allan Hills and the first four seasons in the Yamato Mountains, the total masses collected were 202 and $105 \mathrm{~kg}$ respectively. Iron meteorites made up 16 per cent of the Allan Hills and 0.1 per cent of the Yamato collections; stony-irons equalled 0.3 and 0.1 per cent respectively; ordinary chondrites, 80 and 92 per cent; achondrites, 3.2 and 7.8 per cent; and carbonaceous chondrites, 0.1 and 0.3 per cent respectively. These figures are very preliminary and only useful for the generalized picture they give of major differences in the concentrations on opposite sides of the Antarctic continent. To understand better the distribution of meteorite types in the Allan Hills region, an effort is now being made to map accurately the location of each specimen.

\section{Dynamics of Ice Movement}

In addition to specimen collecting, several members of the U.S. and Japanese teams have been examining the ice motion and concentration mechanism. Their triangulation data has led to a general model illustrated in Figure 8. Newly fallen meteorites will bury themselves in the snow and, as more snow accumulates, sink slowly through the transitional firm zone to the main ice mass. Here they will move at rates of 


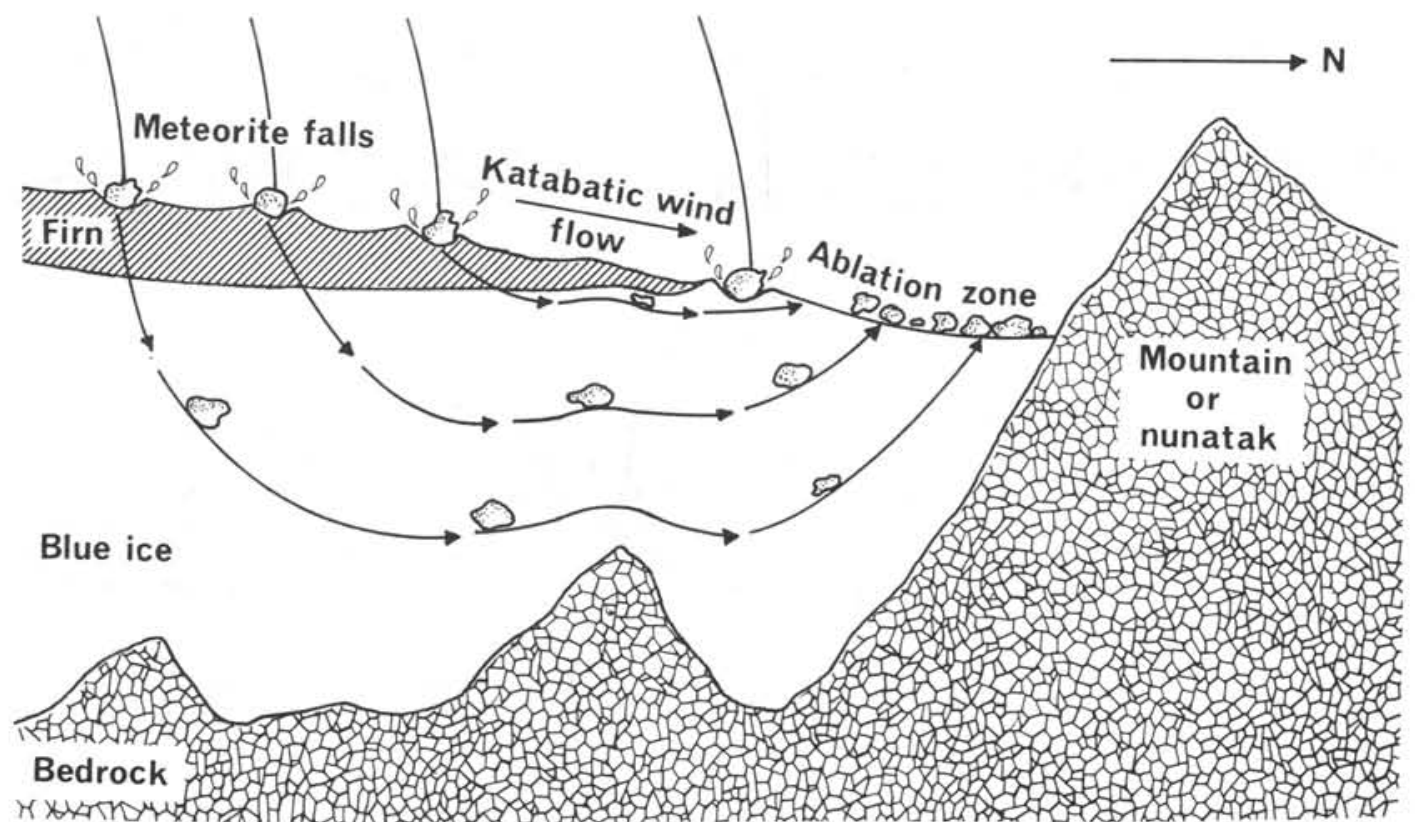

Figure 8: Possible mechanism for concentrating meteorites by ice motion. Specimens falling at random on the spreading ice sheet are carried toward mountain barriers where the flow trajectories are upwards and the ice volume reduced by wind ablation.

several metres per year along the ice flow trajectories spreading radially from the vast Antarctic ice dome. Most will eventually reach the shore where they will be dumped onto a stationary surface or float away in icebergs.

If ice motion is slowed or stopped behind a mountain barrier, an upward push of the ice (at a measured rate of about $5 \mathrm{~cm}$ per year) may combine with the ablation caused by eroding katabatic winds that sweep down the gently sloping Antarctic ice cap to expose old layers of ice and their ancient cargo of meteorites. The concentrations must be transitory features that are created and destroyed as the climate changes and ice flow patterns vary.

\section{Meteorite Searches in the Arctic}

The success of the Antarctic program has aroused interest in the possibilities of finding meteorite concentrations in Greenland and the Canadian Arctic. Expeditions were planned in northwestern Greenland for the past two summers but were not carried out for lack of adequate helicopter support. A party of Canadian geologists searched a portion of northern Devon Island in the summer of 1981 but did not find any meteorites.

In general, several characteristics of the Arctic regions make them appear less promising than the Antarctic. In Greenland and northern Canada the "watersheds" of ice are much smaller than in Antarctica, and the ice is younger, dating back tens of thousands rather than million of years. The Arctic regions are relatively warm and moist and receive many inches of new snow each year, in contrast to the high polar desert of interior Antarctica where the annual increment is measured in millimeters. The northern ice sheets tend to lose volume by melting, which would deposit meteorites in moraines rather than expose them on wind-ablated ice patches. Nevertheless, because areas of bare ice do occur on both sides of the strait separating Canada from Greenland, additional efforts to find them will surely be initiated in the Arctic regions.

Meanwhile, recent calculations by E.J. Olsen suggest that there may be as many as 750000 specimens resident in the east Antarctic ice cap. Because the collections to date have been made at two sites in widely separated localities and covering a total area of around $500 \mathrm{~km}^{2}$, the search for Antarctic meteorite placers is bound to continue with vigour.

\section{Select Bibliography}

Cassidy, W.A. and Rancitelli, L.A., 1982, Antarctic Meteorites: American Scientist, 70, p. 156-164.

Marvin, U.B. and Mason, B., (eds.), 1980, Catalog of Antarctic Meteorites 1977-1978: Smithsonian Contributions to Earth Sciences No. 23, Smithsonian Institute, Washington, 50p.

1982, Catalog of meteorites from Victoria Land, Australia, 1978-1980: Smithsonian Contributions to Earth Sciences No. 24, Smithsonian Institute, Washington, 97p.

Mason, B., 1981, A lode of meteorites: Natural History, 90, p. 62-67.

Nagata, T., (ed.), 1981, Proceedings of the Sixth Symposium on Antarctic Meteorites, National Institute for Polar Research Special Issue 20, Tokyo, 415p.

Olsen, E.J., 1981, Estimates of total quantity of meteorites in the East Antarctic icecap: Nature, 292, p. 516-518.

\section{ABOUT THE AUTHOR:}

Dr. Ursula Marvin is a geologist engaged in mineralogical-petrological research on meteorites and lunar samples at the Harvard/ Smithsonian Center for Astrophysics, 60 Garden Street, Cambridge, Massachusetts 02138 , U.S.A. She is also a part-time faculty member of the Department of Geological Sciences at Harvard University. Also interested in the history of geology, she has written Continental Drift, the Evolution of a Concept, published in 1973. She was a member of the United States meteorite-collecting expeditions to Antarctica in the 1978-79 and 1981-82 field seasons.

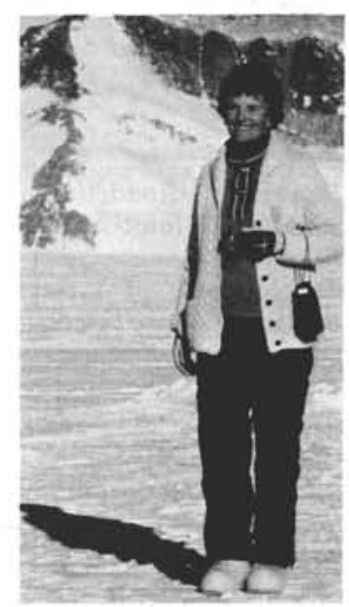

